\title{
Comparison of two laboratory tests in the control of anticoagulant therapy
}

\author{
SARAH J. PEARCE AND A. S. C. SEKAR \\ From Southmead Hospital, Bristol
}

SYNOPSIS A prospective, randomized trial is described in which the usefulness of two tests in the control of anticoagulant therapy is compared. Fifty-two patients were controlled by the one-stage prothrombin time and 55 by the activated partial thromboplastin time. There was no significant difference in the incidence of bleeding between the two groups. When bleeding did occur, it was more often reflected by prolongation of the prothrombin time than of the activated partial thromboplastin time. The prothrombin time was found to have some practical advantages over the activated partial thromboplastin time.

It is well known that current methods for the control of anticoagulant therapy are not very satisfactory (Pollard, Hamilton, Christensen, and Achor, 1962) and minor bleeding episodes have become an accepted hazard of treatment.

The coumarin and indanedione drugs exert their anticoagulant effect by inhibiting the synthesis of clotting factors II, VII, IX, and X. The test most widely used to control anticoagulant therapy is the one-stage prothrombin time based on Quick's technique (Poller, 1969). This test is sensitive to deficiency of factors II, V, VII, and X but is insensitive to a deficiency of factor IX (Denson, 1961).

Haemorrhagic complications may occur when the prothrombin time is within the desired therapeutic range (Pollard et al, 1962), and this is a common clinical observation. Eastham (1968) suggested that the activated partial thromboplastin time was a more valuable test for the control of anticoagulant therapy. This test is sensitive to deficiency of factors II, V, IX, and $X$ but is insensitive to deficiency of factor VII (Nye, Graham, and Brinkhous, 1962).

This paper reports the results of a controlled trial of anticoagulant therapy where half the patients were controlled using the one-stage prothrombin technique and the others by the activated partial thromboplastin time.

\section{Materials and Methods}

One hundred and seven patients were admitted to the trial; they were randomly allocated to be controlled by one-stage prothrombin time (group A) or Received for publication 2 November 1972. by the activated partial thromboplastin time (group B). The initial diagnostic categories of the patients in the two groups are shown in Table I and their age groups in Table II. All patients were initially treated in the wards and were given $\mathbf{4 0 0 0 0}$ units heparin daily by intravenous infusion for five days (except in the case of prophylactic anticoagulation) while oral anticoagulation was begun. The oral anticoagulant used in every case was warfarin, of which 10 to 15 mg was given daily for the first five days to the average patient, this being the regime recommended by Eastham (1971). On the sixth day the prothrombin and activated partial thromboplastin times were measured and these tests were repeated thrice weekly until control was established. Thereafter the tests were carried out at intervals of one to four weeks

\begin{tabular}{llll}
\hline & $\begin{array}{l}\text { Venous } \\
\text { Thrombosis or } \\
\text { Embolism }\end{array}$ & $\begin{array}{l}\text { Arterial } \\
\text { Thrombosis or } \\
\text { Embolism }\end{array}$ & $\begin{array}{l}\text { Prophylactic } \\
\text { Anticoagulation }\end{array}$ \\
\hline Group A & 43 & 7 & 3 \\
Group B & 43 & 6 & 5 \\
\hline
\end{tabular}

Table I Diagnostic categories of patients in group $A$ (controlled by British corrected ratio) and group $B$ (controlled by partial thromboplastin time)

\begin{tabular}{lllll}
\hline Group & Age $(\mathrm{Yr})$ & & & \\
\cline { 2 - 5 } & Under 30 & $30-44$ & $45-64$ & $65+$ \\
\hline (controlled by BCR) & 6 & 12 & 28 & 7 \\
(controlled by PTT) & 11 & 12 & 20 & 11 \\
\hline
\end{tabular}

Table II Age groups of patients in group $A$ and group $B$ 
according to the degree of stability achieved. The dosage of warfarin was adjusted by us. On discharge from hospital all patients were asked to report any untoward bleeding immediately to one of us by telephone or to their own general practitioners. The latter were all informed that the trial was taking place and were asked to report any complication of treatment to us and, in the event of a patient's death, to obtain consent for necropsy if possible. Outpatients were seen by us personally and questioned regarding any abnormal bleeding. Whenever possible, both tests were carried out on the same day as any bleeding episode.

The one-stage prothrombin time was carried out by a method based on Quick's (1942) technique, using pooled plasma from five normal controls and acetone extracted dried human brain reconstituted in phenol saline. The result was expressed as the British corrected ratio (Pollard, 1970) and the therapeutic range chosen was $2 \cdot 0-3 \cdot 0$. The activated partial thromboplastin time was determined using Bell and Alton phospholipid in place of soya bean extract (Eastham, 1968). This result was also expressed as a ratio and the therapeutic range chosen was $1 \cdot 5-1 \cdot 8$. Both tests were carried out routinely on all patients, but for patients in group $A$ only the British corrected ratio was made available to us during the trial and for those in group B only the partial thromboplastin time.

\section{Results}

Over the sixth-month period of study, 107 patients were entered in the trial, making a total of 906 patient weeks of treatment. Fifty-two were controlled by the British corrected ratio (group A) and 55 by the partial thromboplastin time (group B).

Throughout the trial, no episode of further thrombosis or embolism was observed. No haemorrhagic complications were observed in 83 patients. Twenty-nine separate bleeding episodes were noted in the remaining 24 patients, of whom eight were in group A and 16 in group B (Table III). This difference in the incidence of bleeding in the two groups was not statistically significant.

\begin{tabular}{lcccl}
\hline Group & $\begin{array}{l}\text { No. of } \\
\text { Cases }\end{array}$ & $\begin{array}{l}\text { Patient } \\
\text { Weeks }\end{array}$ & $\begin{array}{l}\text { Patients } \\
\text { who Bled }\end{array}$ & $\begin{array}{l}\text { Bleeding } \\
\text { Episodes }\end{array}$ \\
\hline $\begin{array}{l}\text { A } \\
\text { (controlled by BCR) }\end{array}$ & 52 & 484 & 8 & 10 \\
$\begin{array}{l}\text { B controlled by PTT) } \\
\text { Total }\end{array}$ & 55 & 422 & 16 & 19 \\
\hline
\end{tabular}

Table III Incidence of haemorrhagic complications in patients whose anticoagulant therapy was controlled by $B C R$ and PTT
When the trial was concluded the results of both laboratory tests were studied in relation to the bleeding episodes. The British corrected ratio was above the therapeutic range in 21 incidents of bleeding and the partial thromboplastin time in 15 . The nature of the bleeding, the results of the laboratory tests, and the duration of treatment at the time of bleeding are summarized in Tables IV and V. In six

\begin{tabular}{|c|c|c|c|c|}
\hline Case No. & Complication & $B C R$ & PTT & $\begin{array}{l}\text { Duration of } \\
\text { Treatment }\end{array}$ \\
\hline 81 & Vaginal bleeding & $3 \cdot 3$ & $1 \cdot 5$ & 13 wk \\
\hline 69 & Haematuria and epistaxis & $10 \cdot 0$ & $2 \cdot 4$ & 5 wk \\
\hline 2 & Epistaxis & $15 \cdot 0$ & $2 \cdot 5$ & 7 days \\
\hline 80 & Rectal bleeding & $8 \cdot 4$ & $4 \cdot 0$ & 5 wk \\
\hline 45 & Haematemesis & $6 \cdot 8$ & $2 \cdot 1$ & 6 days \\
\hline 45 & Epistaxis & $2 \cdot 6$ & $1 \cdot 1$ & 17 days \\
\hline 11 & Haematuria & $2 \cdot 5$ & $1 \cdot 0$ & 4 wk \\
\hline 11 & Haematuria & 1.9 & $1 \cdot 0$ & 5 wk \\
\hline 7 & Haemarthrosis & $2 \cdot 8$ & $1 \cdot 0$ & 2 wk \\
\hline 85 & Haematuria and epistaxis & \multicolumn{2}{|c|}{ No test done } & 6 days \\
\hline
\end{tabular}

Table IV Bleeding incidents in patients controlled by $B C R$ showing the result of this test, the PTT, and the duration of treatment at the time of bleeding

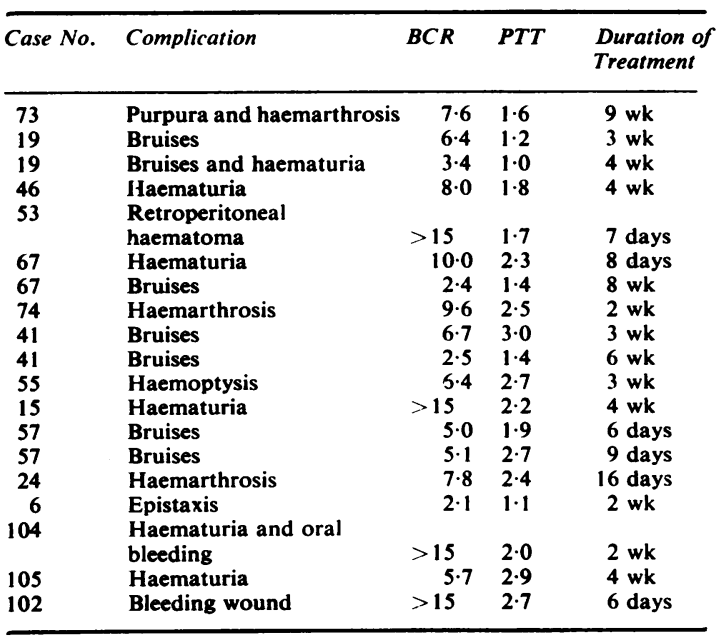

Table $\mathrm{V}$ Bleeding incidents in patients controlled by $P T T$ showing results of this test, the BCR, and the duration of treatment at time of bleeding

incidents the British corrected ratio was above the therapeutic range while the partial thromboplastin time ratio was within or even below the therapeutic range. In no case in this series was the reverse finding observed. This difference between the methods was highly significant $(P<0.001)$. In seven cases both tests were within the therapeutic range (Table VI). 


\begin{tabular}{|c|c|}
\hline Above Therapeutic Range & No. of Bleeding Incidents \\
\hline $\begin{array}{l}\text { BCR and PTT } \\
\text { BCR alone } \\
\text { PTT alone } \\
\text { Neither test } \\
\text { Total bleeding incidents }\end{array}$ & $\left.\begin{array}{r}15 \\
6 \\
0 \\
7 \\
29\end{array}\right\}^{1}$ \\
\hline
\end{tabular}

Table VI Number of bleeding incidents associated with $B C R$ or PTT above and within the therapeutic range

${ }^{1}(\mathbf{P}<0.001)$

Ten patients died during the trial and in one case (no. 104) poorly controlled anticoagulation may have contributed to death. This man, who had very severe mitral stenosis, was anticoagulated following several pulmonary emboli. At necropsy he was found to have a large haemothorax and this may have been the final cause of death in a man already very ill for other reasons. Three patients were found at necropsy to have pulmonary emboli and these were considered by the pathologist and by the clinicians concerned to have taken place before the institution of anticoagulant therapy.

The difficulty experienced in controlling one patient by the partial thromboplastin time is considered worth reporting.

\section{Case Report}

Mrs M.B., aged 42, was anticoagulated following a deep vein thrombosis. She was controlled by the partial thromboplastin time and after three weeks this ratio was only $1 \cdot 2$. The dose of warfarin was increased although it was noted that she had a few small bruises. She stated that she always bruised easily. Four days later she was admitted to hospital with extensive bruising and haematuria. The partial thromboplastin time was then $1 \cdot 0$. For ethical reasons it was considered necessary to ask for the British corrected ratio and this was found to have been above the therapeutic range (at 6.4 and 3.4 respectively) on both occasions. She was therefore withdrawn from the trial and controlled satisfactorily by British corrected ratio for a further eight weeks.

\section{Discussion}

The fact that no patient suffered a further episode of thrombosis or embolism while in the trial suggests that both groups were effectively anticoagulated. Although the difference in frequency of bleeding complications between the two groups was not significant, it was highly significant that in six cases, drawn from both groups, the British corrected ratio was above the therapeutic range while the partial thromboplastin time was within or below the thera- peutic range. In no case was the reverse observed. This supports our clinical impression that the British corrected ratio is a more reliable guide to safe and effective anticoagulation.

Denson (1961) showed that when an oral anticoagulant is administered the levels of the various blood clotting factors fall at different rates. Factor VII is the first to fall and this is reflected in a rapidly lengthening prothrombin time. The British corrected ratio therefore reaches a therapeutic level within $\mathbf{4 8}$ hours. Factors II, IX, and X take much longer to fall and the activated partial thromboplastin time, which is very sensitive to the level of factor IX but totally unaffected by factor VII (Nye et al, 1962), takes nearly a week to reach a therapeutic level and a considerably longer time to become stable. For this reason we followed Eastham's (1971) recommended practice and gave intravenous heparin for five days and the 'loading' dose of warfarin was spread over this period. It might be thought that the greater number of bleeding complications among patients controlled by the partial thromboplastin time was due to the fact that most of our patients were only anticoagulated on a relatively short-term basis, and that bleeding occurred while the partial thromboplastin time was still relatively unstable as compared with the British corrected ratio. We noted, however, that four of the six highly significant episodes mentioned above occurred when patients had been taking warfarin for periods of four to 13 weeks (cases 81, 73, 19, and 46).

Our results conflict with those of Eastham, in whose skilled hands the activated partial thromboplastin time was found to predict bleeding more reliably than the one-stage prothrombin time, although in his series of cases the results of both tests were always available and may have influenced treatment.

We found the partial thromboplastin time to have several practical disadvantages. First, the long period for which it was necessary to give intravenous heparin in many cases prolonged the length of a patient's stay in hospital. Secondly, some patients were inadvertently under- or overanticoagulated during this period as neither test could be used until the sixth day of treatment. Thirdly, we found it more difficult to stabilize the partial thromboplastin time, and patients in group B had to have more frequent tests done. Finally, it has the disadvantage that it has not been standardized on a national basis and is, in fact, a less reproducible test and takes longer to carry out. It is nevertheless, an obviously essential test if abnormalities of factor IX are suspected. In this uncommon instance it might be valuable to use both tests.

In conclusion, we are of the opinion that the one- 
stage prothrombin time is still the best routine test for anticoagulant control.

We would like to express our gratitude to Dr Ian Fraser for his constant advice and criticism during the preparation of this paper and to Miss E. Duncan of the University of Bristol for statistical advice. We are also grateful to Dr R. D. Eastham, Dr F. J. W. Lewis, Dr H. G. Mather, and Dr J. Verrier Jones for their help and encouragement, and to the physicians and surgeons who allowed us to have their patients in the trial.

This work would not have been possible without the help and cooperation of Mr G. A. Crane and the technical staff of the Pathology Department, Southmead Hospital.
References

Denson, K. W. (1961). Levels of blood coagulation factors during anticoagulant therapy with phenindione. Brit. med. J., 1, 1205-1212.

Eastham, R. D. (1968). Improved control of long-term anticoagulant therapy. Brit. med. J., 2, 337-340.

Eastham, R. D. (1971). Personal communication.

Nye, S. W., Graham, J. B., and Brinkhous, K. M. (1962). The partial thromboplastin time as a screen test for the detection of latent bleeders. Amer. J. med. Sci., 243, 279-287.

Pollard, J. W., Hamilton, M. J., Christensen, N. A., and Achor, R. W. P. (1962). Problems associated with long-term anticoagulant therapy: observations in 139 cases. Circulation 25, 311-317.

Poller, L., Editor (1969). Recent Advances in Blood Coagulation, pp. 138-139. Churchill, London.

Poller, L. (1970). The British comparative thromboplastin: the use of the national thromboplastin reagent for uniformity of laboratory control of oral anticoagulants and expression of results. Broadsheet 71, Association of Clinical Pathologists.

Quick, A. J. (1942). The Hemorrhagic Diseases and the Physiology of Hemostasis, pp. 33-36. Thomas, Springfield, Illinois. 